\title{
The Effect of Technological Organization on Cost Innovation and Value Creation
}

\author{
Jintanee Ru-Zhue ${ }^{1}{ }^{\infty}$, Somnuk Aujirapongpan ${ }^{1^{*}}$, Yaninee Songkajorn ${ }^{1}{ }^{\infty}$, \\ Kritsakorn Jiraphanumes ${ }^{1}$ (6)
}

${ }^{1}$ School of Management, Walailak University, Nakorn Sri Thammarat 80110, Thailand.

\begin{abstract}
This research aims to study the effects of technological organization, management of cost innovation, and value creation. The population in this study was the canned and instant food export companies, which are crucial industries that earn incomes for Thailand. The quantitative research method was carried out using questionnaires sent to all companies (census) with the manufacturing managers as respondents. The survey revealed that these companies had a high level of technological organization, value creation, and cost innovation, except for reducing unnecessary functions at a moderate level because the products need to maintain customer demand; therefore, unnecessary adjustments may not be made. PLS-SEM assesses the reflective and structural models to test the research hypotheses. The findings revealed significant influences among three pairs of constructs: (1) technological organization had a positive effect on cost innovation, (2) cost innovation had a positive effect on value creation, and (3) technological organization had a positive effect on value creation. Thus, this research provides empirical information for the influences among the variables and presents the significance of being a technological organization and the inclusion of cost innovation management, to maintain their business during the COVID-19 pandemic and improve the organizational potential for preparation in future circumstances.
\end{abstract}

\section{Keywords:}

Technological Organization;

Cost Innovation;

Value Creation;

Thailand.

Article History:

$\begin{array}{llll}\text { Received: } & 18 & \text { November } & 2021 \\ \text { Revised: } & 09 & \text { January } & 2022 \\ \text { Accepted: } & 01 & \text { February } & 2022 \\ \text { Available online: } & 07 & \text { March } & 2022\end{array}$

\section{1- Introduction}

The consistently increasing world population affects the growing demand for food and agricultural lands [1]. Thailand is one of the countries whose policies promote the significance of food production. One such policy, the Thailand 4.0 policy, attempts to adjust the economic structures by moving toward industrial sectors driven by technology and innovation [2]. This policy encourages general farmers to become 'smart farmers.' It can improve farmers' use of technology and add new knowledge bases for their agricultural applications. Thailand 4.0 enhances productivity. Such agriculture is different from traditional agriculture. Its income is derived from products that generally rely on the weather [3]. Furthermore, the government focuses on food innovation by promoting and establishing the Food Innopolis Project. The project aims to make the country a global food innovation hub, emphasizing research and innovative development for food sciences by supporting human resources and qualitative facilities, with tax rebates for companies participating in the project [4].

Thai government sectors have issued various policies to create food production routes to global markets, attempting to become 'the kitchen of the world,' as Thailand's geography is suitable for plantations [5] and includes fertile coastal areas. These factors enable the country to provide quality ingredients to industrial food production factories. The Thai Ministry of Commerce revealed that in 2019, Thailand exported agricultural products totaling 18,779 million USD,

\footnotetext{
*CONTACT: asomnuk@wu.ac.th
}

DOI: http://dx.doi.org/10.28991/ESJ-2022-06-02-09

(C) 2022 by the authors. Licensee ESJ, Italy. This is an open access article under the terms and conditions of the Creative Commons Attribution (CC-BY) license (https://creativecommons.org/licenses/by/4.0/). 
equating to $7.63 \%$ of its total exports [6]. According to the future trend of increasing food requirements [1], such agricultural industries will have a necessity to produce more. Therefore, companies in the food industry have to increase their potentials, such as knowledge base management, human capital development, and company innovation development, to achieve competitive advantages over their peers worldwide.

Innovation is a crucial factor in driving the progress of both the economic and social sectors in Thailand. Nowadays, due to the high level of competition in the market, it motivates each organization to make an attempt at bringing innovation as an instrument to create competitive advantages. Furthermore, effective cost management of the business can result in lower costs and higher profits. Thus, cost innovation is considered a remarkable tool that helps management with loss mitigation. It can find ways to release the latent potential of existing technologies or out-of-date technologies that can be integrated with different methods. Cost innovation does not change all methods of organization. Instead, it seeks new ways that will increase productivity and be more cost-effective. Changing the materials, which help reduce the cost or improve the production process in new forms, enhances the lower production and operation costs [7]. One example of this is the current situation with the COVID-19 virus. The COVID-19 pandemic is known to affect businesses. Cost innovation is a vital concept that creates the approach to manage the cost of maintaining business during the pandemic and increase the potential for further competition. These are the important reasons for studying cost innovation.

As mentioned above, it demonstrates that cost innovation is a crucial tool to build a competitive advantage for an organization. This study investigates whether or not being a technological organization will affect the use of cost innovation. It also examines whether cost innovation will reduce the value creation for consumers or not. Thus, the research objectives are to assess the level of technological organization and the use of cost innovation in the export companies of canned and instant products in Thailand at present. Then, the researchers will study the effects of being a technological organization, cost innovation, and value creation in the organization. The research result will assist in streamlining the model of organization development further and can be applied to use in the companies of canned and instant food industries as well as other industries.

The remainder of the article is organized as follows. After presenting the study justification in the introduction, the second section presents the literature review, variable definitions, and research framework. The third section details the methodology, research design, measurement, and data analysis. The following section details the results and the structural model. Finally, in the discussion and conclusion section, the results are compared with the determinants found in the literature. Furthermore, the suggestion for adapting the research results into practice is mentioned in this part.

\section{2- Literature Review}

\section{2-1- Technological Organization}

Technological capability implies the various technical resources involved in design, production, and information, including seeking and collecting external knowledge [8]. Technological capability is a company's ability to design and develop products or processes in a new form. This includes the improvement of knowledge and specific skills. It also involves adapting knowledge in terms of its advisory or performance capabilities to create more effective company performance [9]. Furthermore, technological capability can extend and adjust a company's main competencies, acquiring various technologies and management with all its technological resources [10]. Such technological capability comprises operational knowledge, methods, processes, experiences, and instruments [11].

The inability of the organization to become a technology organization is mainly due to a lack of support from top management and inappropriate organizational structure; as a result, creating and sharing knowledge are not efficient [12]. The perceptions of learning and behavioral intentions are vital to operation in the workplace because they support a technological organization to identify opportunities and solve complex issues [13]. An empirical study of the motivation to evolve into a technology organization significantly depends on intra-organizational motivation to increase operational efficiency and competitive advantage. The result does not find the influence of external motivation, such as competitors, suppliers, and customer pressure [14].

Many academics have studied technological capability previously. It is measured through organizations' technology levels covering various activities, such as R\&D, marketing, technology, innovation, products, and services. Digital transformation is a part of a technological organization. It concerns the changes in digital technologies and brings about an organizational business model that results in improved products, processes, and organizational structure [15]. The technological level of organization is the level of usage, level of technology and intellectual property in production processes that increase production efficiency, product quality, and crucial social effects. The study analyzes organizational technology in seven aspects, as follows. (1) Application of production technologies: a measurement of the application of modern production technologies, increases in productivity of machines and equipment, the efficiency of the production process, assets saving, market expansion, and the effects of the organization's technological level and competitiveness. (2) Objectives of applying specific technology types: this considers the technological applications, 
especially resource and energy savings, environmental conservation, and increases in productivity and product quality. (3) Application level of advanced production technologies: this measures the use level of technological types in an organization. (4) Level of developed and applied key technologies in priority areas: crucial technology is a mechanism to increase the productivity of R\&D, which affects the rapid advancement of economic growth and generates competitive advantages. (5) Application of intellectual property: the intellectual property created through R\&D helps companies create products that can compete in the global market and support the company's innovative activities. (6) Factors providing a competitive advantage to organizations: this indicates the factors affecting competitive advantages, which consists of the product price, product quality, new forms of the product, the response to consumers' requirements, as well as the level of production technology, service, and after service. (7) Factors contributing to increasing an organization's technological level: this explores various factors affecting the technology level, such as consumers' needs, marketing competition, and laws or new standards [16]. In this research, the components of technological organization are as follows.

Operating capabilities: This is the capability to use existing technologies efficiently [17]. When an organization's executives enhance company technology, it will drive operations activities to increase knowledge, skill, and experience. This includes seeking, receiving, and absorbing technologies from various sources and applying them to adjust firm performance. In addition, employees will be skillful and adapt the technology to their products and processes, using these technologies effectively [18].

Improvement capabilities: This capability is relevant to imitating and using creative ideas derived from external sources for technologies [18]. The capability involves using the necessary skills and information to perform production, maintenance, and repairs. Furthermore, it has to adjust the technologies to increase production and performance effectiveness to obtain better results [19].

Learning capabilities: This capability is the organizational learning process management uses to acquire the knowledge base [18]. It consists of the skills and information necessary for originating technical and organizational changes, including maintenance of such changes [20]. It also includes repeatability, technique system adjustments, product or process creation, new technological design, organizational learning mechanism existence, and utilizing learning mechanisms from external organizations. These are considered the crucial components of dynamic learning capability [21]. In conclusion, learning capabilities are derived from various sources, such as learning, operating, using, interacting with each other's processes, seeking knowledge, and performing R\&D within the company [19].

\section{2-2- Cost Innovation}

Innovation has been promoted for several years through global economic system changes. These changes include trade liberalization, open borders for product and service transfers, technological development funds, and organizational performance alterations [22]. Although most of the innovations have originated from developed countries such as the United States, the United Kingdom, and Japan, the new market has a competitive advantage over developed countries in terms of workforces because of lower wages. This results in multinational companies establishing their production bases in emerging markets to bring the products and processes developed in lower-cost countries back to their own nations [23]. Cost innovation is the cost advantage of the developing country's innovation improvement at a lower price [24].

Innovation is a development or new creation in products and services through quality increase over existing ones, a process driven by intense market competition. This impacts on the insufficient spending on research and development in advanced technology. Therefore, many companies focus on lowering production costs by reducing the workforce. Some organizations realize the opportunities in developing countries. It is possible to use cost innovation through three methods: (1) Product offerings, bringing high technology to mass-market customers at lower prices. This helps remove the former framework that advanced technologies were limited only to high-end products. (2) Product offerings appropriate to each specific customer's needs. Responses to the various needs of customers cause high costs. However, because of the numerous labor efficiencies in developing countries, it is a possible strategy, and is reciprocated with better customer satisfaction. (3) Moving products from niche markets to the mass market, unlocking customers' latent needs, and changing market competitiveness [7].

Innovation and cost usually clash with each other. However, if they work together, they will affect the adjustment of marketing structures by building a long-term competitive advantage [25]. These researchers also define the meaning of castigation as an innovation for cost reduction. Additionally, it can satisfy customers at a suitable level or possibly a better level with fewer offers. It is concordant with the concept of frugal innovation, which describes product, service, systems, and business model designs that reduce complexity. At the same time, it gives value to the users at an economical price by focusing on price-sensitive, low-income customers [26, 27] who need products and services adjusted according to their needs [28]. Remarkably, frugal innovation is of social and economic value to numerous people as it uses fewer financial and natural resources [29]. Frugal innovation has three consideration criteria: (1) Substantial cost reduction (2) Concentration on core functionalities by reducing the complexity of products or services. Thus, they are easy to use, economical, environmentally-friendly and are suited to consumers' behaviors and livelihoods. (3) Optimized performance level where operation and engineering qualities such as speed, power, durability, and accuracy suitably 
respond to market needs at a lower price [30]. Collecting data about local people's needs to adjust products or services directly to their local requirements is considered necessary. It should discern the differences between various factors, such as culture, language, and public utilities [31]. The key to cost innovation is the reduction of the cost, while retaining the quality of the products and responding to low-income people's needs in developing countries $[32,33]$. In this research, the components of cost innovation include the following.

Cost reduction: Cost innovation characteristically means making products or services at a lower cost than other products or services [30]. Building cost advantages by exploiting emerging markets, especially like China does in response to global customers' needs by increasing value and reducing costs simultaneously [7]. Frugal innovation is defined as a designed product, service, system, and business model that reduces complexity and lifecycle costs. This affects the reduction of production costs, such that the products are not too expensive [34]. Furthermore, it is responsive to the needs of low- and middle-income earners [35]. Cost reduction approaches can use the circular economy notion by reducing the environmental impacts, e.g., using fewer resources, wasting less, lasting longer, and encouraging reuse methods [36]. Applying this concept not only reduces the cost of production but also protects the environment.

Reducing unnecessary functions: This emphasizes the elimination or reduction of certain elements from a product to reduce its cost. When a product is complicated or consists of too many functions, it also has an engineering plan that requires higher capital [35]. Raw materials, labor, and production time used for creating the product are considered costs. Some markets have been getting enough. Therefore, the firm should review its products or services which have not responded to customer needs yet. This might be in the form of the product's price, service, or the product itself. Price affects customer decision-making the most because online marketing growth makes product comparisons easy. However, no matter how many functions are reduced in any aspect, the product or service should remain responsive to maintaining customer satisfaction [25].

Using innovation: The company should depend on its resources to create an activity model that generates lower costs or differentiation advantages. Numerous companies can reduce their costs and build a differentiation advantage at the same time (dual strategy). A company ought to apply innovation or technology in spaces already occupied by that company [37]. The organization with high-performance results must develop itself and consistently establish competence, quickly adjusting to changing environments [38]. The capability to innovate is an ability that needs to be applied to create products, services, and processes, including new forms of management for building sustainable competitive advantages [39]. New methods and management may create cost reductions in areas such as raw materials, labor, and time.

Technology adjustment capabilities and innovation capabilities are difficult to separate. According to the study, innovation may originate from routine activities directly relevant to production rather than activities specifically emphasizing innovation. However, both of the capabilities mentioned above are considered change capabilities [40]. There are studies that investigated motivations for developing technological organizations. One of the main motivations is cost reduction $[14,41]$. Technological capabilities ensure that technology selection is suitable for its task. The ability to absorb, adjust, and develop technology, update processes, and design new products is a local innovation [42]. Production costs and quality are indicators of technological capabilities absorbed through learning capabilities [43]. Furthermore, when a company has good learning capability, it will enhance its information and knowledge base; applying this base in product and service development will reduce unnecessary features, yet the product or service will still satisfy the customer [25]. Technological capability is a crucial factor for creating and producing innovation within a company. Generally, it involves the necessary knowledge and skills for performance development, absorption, adjustment, and technology transfers [44]. These processes are essential for taking an existing knowledge base and extending it to develop new initiatives that match the customers' specific needs. Therefore, this research advances the following hypothesis:

H1. Being a technological organization positively affects the cost innovation management.

\section{2-3- Value Creation}

Value creation is divided into two types. 1) Use value is the specific quality of new work, products, or services perceived by the users, regarding user requirements such as speed, quality, aesthetics, or effectiveness. Such decision making is an individual decision. 2) Exchange value is measured by the perceived amount of money required for products or services, which is the amount of money the users spend to acquire that work, product, or service. The definition considers the users' perceived values, be they individuals, organizations, or society. Finally, this perception will change from the value that the users derive in exchange for money. Generally, this exceeds manufacturer costs (such as money, time, raw material, labor, and effort) in various forms of value creation [45].

Value creation is defined as to how users evaluate the novelty and appropriateness of new work, products, or services. When considering value creation, it can be analyzed at three levels. (1) Individual level: it creates value for new work, products, or services that generate more benefits or reduces costs per unit to a greater degree than other choices. (2) Organizational level: whether the company will succeed depends on its ability to present newer and better values to its customers. Such competence is contemplated in the application of knowledge by employees. Ultimately, it will become 
a crucial innovation base for value creation for targeted customers. The characteristics of the organizational level include invention, innovation, knowledge creation, and management. (3) Societal level: the value creation process can originate in the form of incentives for entrepreneurs. The purpose is twofold: to support existing organizations and support new entrepreneurial investments to expand value to society [46]. This research emphasizes value creation at an organizational level by focusing on three components, including the following.

Innovation generating: New product development (NPD) will be crucial in business performance and increasing innovation in the quickly changing the current environment [47]. The new value will be generated when a company develops or invents new methods using technologies or materials in a new form. Companies will bring about product differentiation and cost reductions, such as applying a new process for speeding up production to reduce the cost per unit of a certain product. Therefore, the analysis of innovation creation will be an activity that affects the value creation process. Organizations with innovations can propose new products, services, or management [37]. Furthermore, companies tend to create novel things when facing uncertain environments [48]. To focus on the targeted users' benefits regarding new products or services, Value creation is relevant to the innovation created and increased customer values in the form of benefits on consumption [49]. Value creation is done at an organizational level. This includes the activities that add more novelty or benefits to users or targeted customers and motivates them to pay money to acquire such specialties [46].

Competitive advantages: The organization can create value by focusing on the way it generates competitive advantages. A company can create advantages through outstanding organizational processes. Asset positions and evolutionary paths will help create the integration and determine the capability value, both internally and externally [50]. The capability is creative and adjusts performance routines until they become competitive advantages [51]. The research mostly emphasizes a company's internal factors (knowledge creation, learning, and being entrepreneurs) concerning the generation of these new advantage forms. However, it neglects the significance of perception, requirement, and alternation of the targeted users [46].

Knowledge creation: The process of organizational knowledge creation is important. This new knowledge can lead to targeted customers receiving more value. The social connections increasingly affect a person's company. Companies receive information and grow their knowledge base from the process of collecting and exchanging information. It originates in an organization's novel knowledge base [52]. Furthermore, emphasizing external social networks to determine customers' and users' needs or compare rivals' products will increasingly generate positive effects on novel and suitable innovations. The organizational boundaries become more flexible, allowing the integration between internal resources and external cooperation. The outside cooperation, open innovation, will increase the benefit of knowledge sharing throughout partnerships and networks [53]. Some knowledge may originate from the company's research and development (R\&D). A successful company depends on its capabilities. It proposes values to customers with better novelty by receiving and bringing in existing knowledge [46].

Technological capability is the ability to work through a company's technology activities [54]. Technical management indicates use, maintenance, and improvement. If used in combination with other capabilities, it can increase the organization's strength for building competitive advantages [11]. Technological development in the company enhances crucial knowledge. Therefore, technological capability is an essential part of knowledge integration. The knowledge received from any source can be applied to develop the organization [55]. Learning capability is a company's quality that focuses on enhancing and promoting learning processes [56]. It includes the necessary resources for diagnosis, employee training, business activity assessment, and transferring employee information and knowledge. This knowledge will help increase the effectiveness of innovation, performance, and competitive advantage [57]. A successful company continuously creates a competitive advantage superior to other companies through its learning capability development. Therefore, learning in an organization is a crucial factor for value creation [58]. Based on the above-mentioned discussion, this study presents the following hypothesis:

\section{H2. Being a technological organization positively affects value creation.}

Developing products that fulfill customer needs is a crucial strategic target [59]. Company capabilities impact the global market for competitive efficiency. Production costs influence it; thus, effective cost reduction will generate the activities that create value for the organization [60]. In addition, this has competitive advantages [61], as customers give products or services monetary value from two component factors: price and consumer surplus. Thus, manufacturers have two alternatives. The first is to maintain the price of products and increase consumer surplus. The second one is to reduce the product price and increase consumer surplus; this increase will satisfy customers [45]. Developing efficient innovations may come from the idea of reducing something unnecessary but still maintaining the targeted customer's satisfaction [25]. These factors maintain or reduce consumer surplus. Product prices will decrease from a cost reduction to a decrease in unnecessary features. Doing so reduces the product's financial value and changes the company's marketing perspective. Innovation activities affect a firm's efficiency [62]. Thus, the researchers formulate the following hypothesis:

H3. Cost innovation management positively affects value creation. 


\section{3- Methodology}

\section{3-1- Research Design}

The sampling frame is consistent with the research focusing on the canned and instant food export companies in Thailand. These companies are in the agro-industry generating higher revenues (33\% of sector incomes) than other exporters. The study emphasizes three main sectors: fruit, vegetables, and seafood. They use high technology in production and usually focus on cost strategy. For these reasons, the mentioned sectors are interesting for studying technological organization and cost innovation. According to the examination of a list of companies registered with the Ministry of Commerce, there were 503 companies (June 2020). There was a pandemic of COVID-19 during the study period. As a result, many of the list companies went out of business. Thus, the researchers decided to collect data from all companies (census).

The questionnaire was developed from the literature review. Content validity was estimated by five experts who had in-depth knowledge about innovation management. Then, the pilot test was carried out by 30 companies to investigate the reliability with Cronbach's alpha coefficient. Each question item had a value higher than 0.8. After the questionnaire was validated and considered reliable, the researchers collected the data by telephone and email. The researchers introduced and elaborated about this study to each company's production manager or CEO, who completely understood the intricacies of the company. The questionnaires would be sent via email to those managers directly. Within the questionnaires, the definitions of each variable were briefly presented to create a clear understanding. The result revealed that, out of 503 companies, 146 companies could not be contacted, and 59 companies refused to disclose their proprietary information. Therefore, the research staff delivered 278 questionnaires and received 63 questionnaires. Figure 1 presents the research methodology in a flowchart. The bias was tested by comparing 30 data sets the first and final time. The results revealed that there was no significant difference, so the data had a non-response bias.

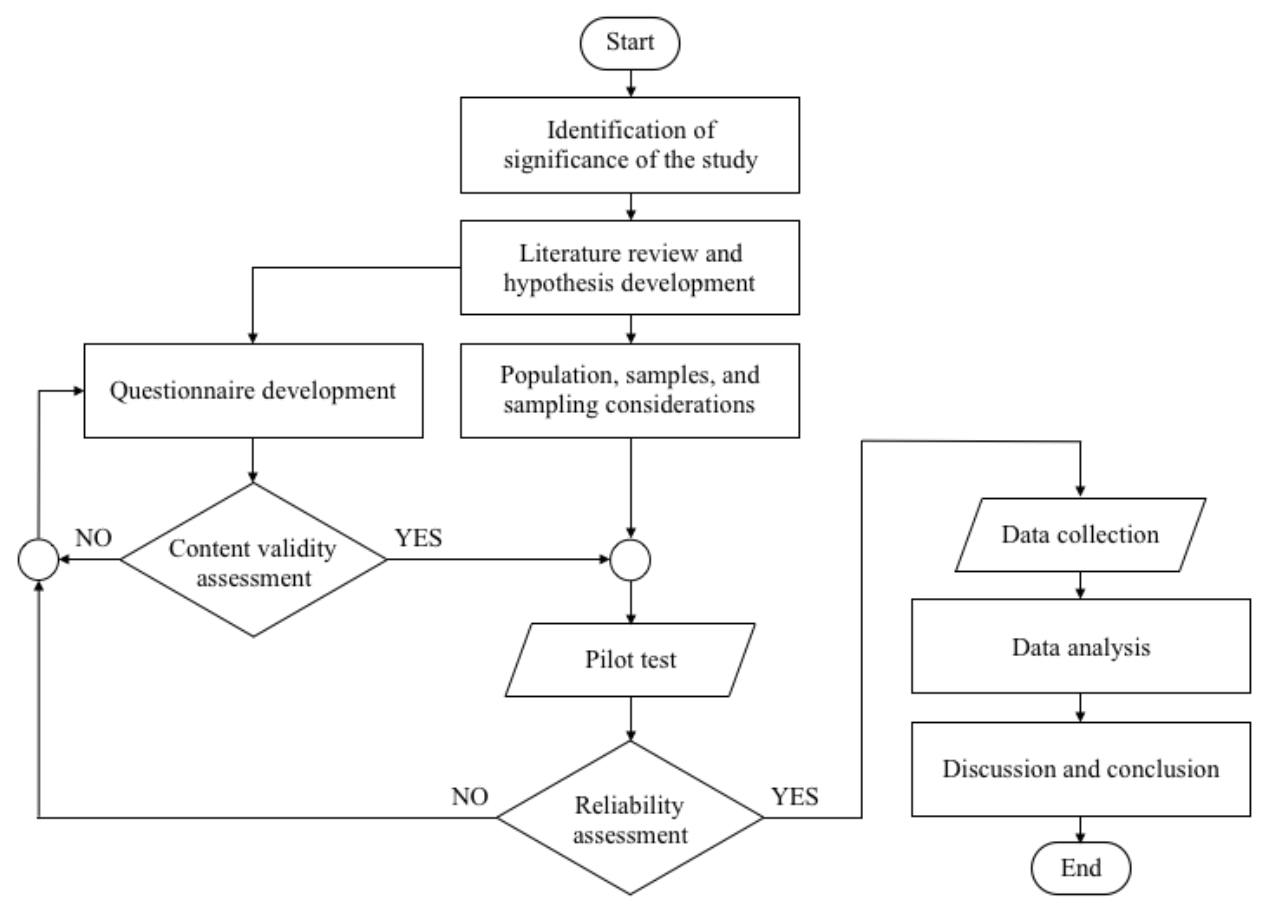

Figure 1. Flowchart of research methodology

The sample size was examined in this study using the inverse square root and gamma-exponential methods [63]. With the statistical power at 90 percent for the 0.05 significance level, the minimum required sample sizes are the inverse square root method estimate 59 samples and the gamma-exponential method estimate 44 samples. Therefore, the number of questionnaires received from 63 data surveys is sufficient for this research.

\section{3-3- Measurement}

The questionnaires include four parts; the characteristics and the question items on technological organization, cost innovation, and value creation in the organizations, respectively. Most of the questions are measured on a 5-point Likert scale, from 1 (strongly disagree) to 5 (strongly agree). All model structures were measured from the indicator starting from technological organization (11 questions), cost innovation (11 questions), and value creation (12 questions).

\section{3-4- Data Analysis Methods}

The data analysis began with examining the level of indicators for each variable and exhibiting descriptive statistics of the data from the sample. There were three levels according to the mean of data: the low level was between 1.00-2.33, 
the moderate level was between 2.34-3.66, and the high was between 3.67-5.00. The conceptual model was analyzed by PLS-SEM. The reflective measurement model assessment considered indicator loading, internal consistency reliability, convergent validity, and discriminant validity. Additionally, the structural model was respected from collinearity, $\mathrm{R}^{2}$, predictive relevance $\left(\mathrm{Q}^{2}\right)$, and PLSpredict [64]. Finally, the effects among the three constructs confirm the research hypothesis established.

\section{4- Results and Discussions}

\section{4-1- The Descriptive Statistics}

According to the data collected, the descriptive statistics of the samples are shown in Table 1. When considering the mean of each indicator and comparing it with the criteria (specified in section 3-3), it reveals that almost all of the observed variables at present are at a high level but reducing unnecessary functions is the medium level. As a result, it can be concluded that these companies have high-level technological capabilities. These companies support the development and application of technologies for production, adjusting or improving the production processes to increase the productivity and efficiency of operations, and promoting technological learning in companies to further grow such knowledge for company development. In cost innovation, cost reductions and using innovation are at a high level because the companies use cost strategy and innovation to reduce their costs. Since the canned and instant foods are not easy to adjust or reduce unnecessary functions because they may affect operations, ranging from the raw materials to the tastes of products. In other words, the change depends on motivation, benefit, and difficulty issues affecting the quality management systems [65].

Table 1. Descriptive statistics of the samples

\begin{tabular}{cccccccc}
\hline Constructs & Level & Mean & Min & Max & Var & Skew & Kurt \\
\hline & Technological Organization & & & & \\
\hline Operating Capabilities & High & 3.881 & 2.250 & 5.000 & 0.516 & -0.118 & -0.901 \\
Improvement Capabilities & High & 3.857 & 2.670 & 5.000 & 0.418 & 0.143 & -0.662 \\
Learning Capabilities & High & 3.726 & 2.250 & 5.000 & 0.505 & -0.135 & -0.688 \\
\hline \multirow{2}{*}{ Cost Reduction } & Cost Innovation & & & & \\
\hline Reducing Unnecessary Functions & Hedium & 3.614 & 1.000 & 5.000 & 0.592 & -0.596 & 1.173 \\
Using Innovation & High & 3.845 & 2.750 & 5.000 & 0.373 & 0.251 & -0.680 \\
\hline & Value Creation & & & & & -0.621 \\
\hline Innovation Generating & High & 3.841 & 2.000 & 5.000 & 0.478 & -0.398 & -0.425 \\
Competitive Advantages & High & 3.976 & 2.500 & 5.000 & 0.423 & -0.074 & -0.632 \\
Knowledge Creation & High & 3.841 & 1.750 & 5.000 & 0.529 & -0.241 & -0.096 \\
\hline
\end{tabular}

\section{4-2- Goodness-of-Fit}

The overall Goodness-Of-Fit (GoF) was assessed via the standardized root mean square residual (SRMR), geodesic discrepancy $\left(\mathrm{d}_{\mathrm{G}}\right)$, and unweighted least squares discrepancy $\left(\mathrm{d}_{\mathrm{ULS}}\right)$, which were below the $95 \%$ quantile of the corresponding reference distribution $\left(\mathrm{HI}_{95}\right)$. Considering that certain values did not meet the criteria, the authors considered them below the $99 \%$ quantile $\left(\mathrm{HI}_{99}\right)$. Table 2 shows the results of the discrepancy measures for $\mathrm{HI}_{95}$ and $\mathrm{HI}_{99}$. Overall, the model had a good fit.

Table 2. Model fit assessment

\begin{tabular}{ccccc}
\hline Discrepancy & Value & HI $_{\mathbf{9 5}}$ & HI $_{\mathbf{9 9}}$ & Conclusion \\
\hline SRMR & 0.078 & 0.070 & $\mathbf{0 . 0 7 9}$ & Supported \\
$\mathrm{d}_{\mathrm{ULS}}$ & 0.276 & 0.222 & $\mathbf{0 . 2 8 0}$ & Supported \\
$\mathrm{d}_{\mathrm{G}}$ & 0.221 & $\mathbf{0 . 2 6 0}$ & $\mathbf{0 . 3 1 3}$ & Supported \\
\hline
\end{tabular}

\section{4-3- Reflective Measurement Models}

In the reflective measurement model assessment (Table 3), the authors first inspect the factor loadings that recommend the value above 0.708 because the construct can explain more than 50 percent of the indicator variance. The finding suggests that all loadings are concordant with the criterion; thus, providing acceptable reliability of all indicators. In the following step, the authors consider internal consistency reliability from Cronbach's alpha, rho_A, and rho_c (Jöreskog's 
composite reliability). Rho_A is used to indicate a construct's internal consistency reliability when the value is between 0.700-0.900 and is usually between Cronbach's alpha (lower bound) and rho_c (upper bound) [64]. The results of this research are within the given criteria. Thus, all indicators are correlated to measure the same construct in this model. Then, convergent validity is considered from the average variance extracted (AVE) that should be higher than 0.500. The findings follow the criteria; as a result, it refers to the construct explaining more than 50 percent of the variance of its indicators. The last step is to evaluate the discriminant validity as the boundary to which a construct is empirically specific from others in the structural model. It ensures that the different constructs measure different characteristics (Table 4, Fornell-Larcker criterion). The AVE values presented in the diagonal of the matrix must be higher than the correlation value in the identical column and row. The findings follow the criteria. Some researchers argue that the Fornell-Larcker criterion is unsuitable for discriminant validity assessment. Thus, the heterotrait-monotrait (HTMT) ratio of the correlations proposed by Henseler, Ringle, and Sarstedt [66] will have issues when the values are lower than 0.900 , when constructs are conceptually homologous and conversely, less than 0.850 . This study has different concepts; therefore, the authors choose a criterion of 0.850. All values of HTMT are fewer than the given criterion (Table 4, Heterotrait-Monotrait ratio). Thus, each construct in the model measures different characteristics.

Table 3. Factor Loading, Collinearity (VIF), Internal Consistency Reliability, and Convergent Validity

\begin{tabular}{|c|c|c|c|c|c|c|}
\hline Constructs & Loading & VIF & Alpha & rho_A & rho_c & AVE \\
\hline Technological Organization & & & 0.916 & 0.920 & 0.947 & 0.855 \\
\hline Operating Capabilities & $0.908 * * *$ & 2.527 & & & & \\
\hline Improvement Capabilities & $0.941 * * *$ & 4.482 & & & & \\
\hline Learning Capabilities & $0.926^{* * *}$ & 3.976 & & & & \\
\hline Cost Innovation & & & & 0.890 & 0.914 & 0.781 \\
\hline Cost Reduction & $0.919 * * *$ & 3.067 & & & & \\
\hline Reducing Unnecessary Functions & $0.788 * * *$ & 1.663 & & & & \\
\hline Using Innovation & $0.936 * * *$ & 3.380 & & & & \\
\hline Value Creation & & & & 0.885 & 0.924 & 0.803 \\
\hline Innovation Generating & $0.918 * * *$ & 3.648 & & & & \\
\hline Competitive Advantages & $0.825^{* * *} *$ & 1.789 & & & & \\
\hline Knowledge Creation & $0.942 * * *$ & 4.193 & & & & \\
\hline
\end{tabular}

Note: $* * * \mathrm{p}<0.001$, one-tailed test.

Table 4. Discriminant Validity and correlation

\begin{tabular}{cccccccccc}
\hline \multirow{2}{*}{ Constructs } & \multicolumn{3}{c}{ Fornell-Larcker Criterion } & \multicolumn{2}{c}{ Heterotrait-Monotrait Ratio (HTMT) } & \multicolumn{3}{c}{ Correlation } \\
\cline { 2 - 10 } & $(\mathbf{1})$ & $\mathbf{( 2 )}$ & $\mathbf{( 3 )}$ & $\mathbf{( 1 )}$ & $\mathbf{( 2 )}$ & $\mathbf{( 3 )}$ & $\mathbf{( 1 )}$ & $\mathbf{( 2 )}$ & (3) \\
\hline (1) Technological Organization & 0.855 & & & & & 1.000 & \\
(2) Cost Innovation & 0.409 & 0.781 & & 0.702 & & 0.639 & 1.000 & \\
(3) Value Creation & 0.597 & 0.517 & 0.803 & 0.862 & 0.817 & 0.719 & 0.773 & 1.000 \\
\hline
\end{tabular}

\section{4-4- Structural Model and Hypotheses Testing}

Structural model coefficients for the relationships between the constructs originate from evaluating a set of regression equations; consequently, the authors must analyze collinearity to be confident that there is no bias in the regression results. When predictor variables in the same regression model are correlated, they cannot independently predict the value of the dependent variable. The variance inflation factor (VIF) values used for inspection should be fewer than 3 . According to the findings, the minority of VIF values meet the defined criteria (Table 3). The others are between 3 and 5; as a result, there are possible collinearity issues [64]. Although some criteria of VIF value occurs, collinearity issues are suggested to be higher than 5 [67], the researchers will address this point in the limitations.

Examining the predictive power of the structural model, the authors consider three instruments: $\mathrm{R}^{2}, \mathrm{Q}^{2}$, and PLSpredict. The $\mathrm{R}^{2}$ value is between 0 and 1 , with greater values exhibiting a higher explanatory power. As a guideline, $\mathrm{R}^{2}$ values of $0.75,0.50$, and 0.25 can be assessed as substantial, moderate, and weak [64]. The results of $\mathrm{R}^{2}$ (Table 5) presented explanatory power of cost innovation as weak, but value creation is presented as moderate. Nevertheless, the $\mathrm{R}^{2}$ value only indicates the model's in-sample explanatory power. Consequently, it is inappropriate to assess the predictive power with only $\mathrm{R}^{2}$ [68]. 
Predictive accuracy assessment of the model can be derived from the $\mathrm{Q}^{2}$ value estimated by the blindfold technique. The procedure will forecast the data points removed for every variable. The differentiation between the predicted and original values is solved to $\mathrm{Q}^{2}$ values, indicating predictive accuracy. Although $\mathrm{Q}^{2}$ is not a measure of out-of-sample prediction, it combines aspects of out-of-sample prediction and in-sample explanatory power [69]. As a guideline, $\mathrm{Q}^{2}$ values greater than $0,0.25$, and 0.50 represent the small, medium, and large predictive relevance of the PLS-path model [64]. The findings of $\mathrm{Q}^{2}$ (Table 5) present the predictive accuracy of cost innovation as medium, and value creation as large.

The method for the out-of-sample prediction involves estimating the model on an analysis sample and assessing its predictive performance on the data that are not the collected sample [69]. The PLSpredict method is developed for outof-sample-based predictions in PLS-SEM. In the beginning, the $\mathrm{Q}^{2}$ predict value, evaluated to verify that the model outperforms the most naïve benchmark, has to be greater than zero (Table 5). Then, by the PLSpredict method, the authors compare the root mean squared error (RMSE) between the value from PLS-SEM and the naïve benchmark (linear regression model: LM). The findings (Table 5) exhibit that the majority of RMSE values of cost innovation in the PLSSEM analysis is greater than the naïve benchmark (LM). It refers to low predictive power. Conversely, the minority of RMSE values of value creation in the PLS-SEM analysis is higher than the naïve benchmark (LM); as a result, it refers to medium predictive power [64]. According to a multifaceted consideration, in conclusion, the resulting structural model can explain the cost innovation construct at the relatively low level and the value creation construct at the medium level.

Table 5. Assessing structural model

\begin{tabular}{|c|c|c|c|c|c|}
\hline \multirow{2}{*}{ Constructs } & \multirow{2}{*}{$\mathbf{R}^{2}$} & \multirow{2}{*}{$\mathbf{Q}^{2}$} & \multirow{2}{*}{$\begin{array}{c}\mathbf{Q}_{\text {predict }}^{2} \\
\text { (PLS-SEM) }\end{array}$} & \multicolumn{2}{|c|}{ PLSpredict } \\
\hline & & & & RMSE (PLS-SEM) & RMSE (LM) \\
\hline Cost Innovation & $\begin{array}{c}0.409 \\
\text { (weak) }\end{array}$ & $\begin{array}{c}0.310 \\
\text { (medium) }\end{array}$ & 0.377 & \multicolumn{2}{|c|}{ low } \\
\hline Cost Reduction & & & 0.373 & 0.512 & 0.525 \\
\hline Reducing Unnecessary Functions & & & 0.135 & 0.723 & 0.721 \\
\hline Using Innovation & & & 0.355 & 0.496 & 0.487 \\
\hline Value creation & $\begin{array}{c}0.683 \\
\text { (moderate) }\end{array}$ & $\begin{array}{c}0.528 \\
\text { (large) }\end{array}$ & 0.573 & \multicolumn{2}{|c|}{ medium } \\
\hline Innovation Generating & & & 0.423 & 0.529 & 0.520 \\
\hline Competitive Advantages & & & 0.425 & 0.496 & 0.522 \\
\hline Knowledge Creation & & & 0.526 & 0.504 & 0.523 \\
\hline
\end{tabular}

Note: PLSpredict is the comparison of the MAE values between PLS-SEM and LM. The bold numbers indicate the higher values for each indicator.

This study uses PLS-SEM to compute the structural equation to test the hypotheses on the relationship and influence of the technological organization, cost innovation, and value creation. The result of the structural model is presented in Figure 2. When considering the direct relationships among the constructs (Table 6), the findings show that being a technological organization has a significant positive effect on cost innovation management $(\beta=0.639, \mathrm{t}=8.234, \mathrm{p}=$ 0.000). Therefore, H1 is supported. Being a technological organization increases capacities for seeking and applying technological uses efficiently, developing and improving existing technologies, and enhancing technological learning. Technology absorption, technological capability, and learning capability have a relationship with the production cost and production quality of the company [43]. As this study defines a technological organization as an organization that intensively operates, improves, and learns technology, the findings are compared in the context of the three activities on many kinds of technologies. Digital technology is the essence of the digitalization of data and information.

Digital transformation is the method to take advantage of digital opportunities, drive innovation, and affect a business overall [70]. The digital platforms provide matches between producer and consumer [71]. Digital technology encourages the development of innovation to increase productivity and reduce costs [72]. The digital business platform also facilitates companies to understand the actual needs of consumers [73]. Thus, such technology allows companies to synthesize cost innovations from the received data. There are studies that investigated motivations for developing technological organizations, the results of which found that the main motivations are cost reduction and quality, speed, and efficiency improvement $[14,41]$. The results of this study prove that being a technological organization facilitates cost innovation management. Thus, it confirms that cost reduction can exist when the organization focuses on technology. In other words, the technological organization supports the company in achieving potentially greater readiness than other companies. Then, cost innovation management promotes the introduction of various innovations created from organizational technologies, such as product, process, or management innovations, to reduce cost. There is research that has confirmed that the adoption of internet technologies can reduce advertising, marketing, operating, and inventory costs [74]. 


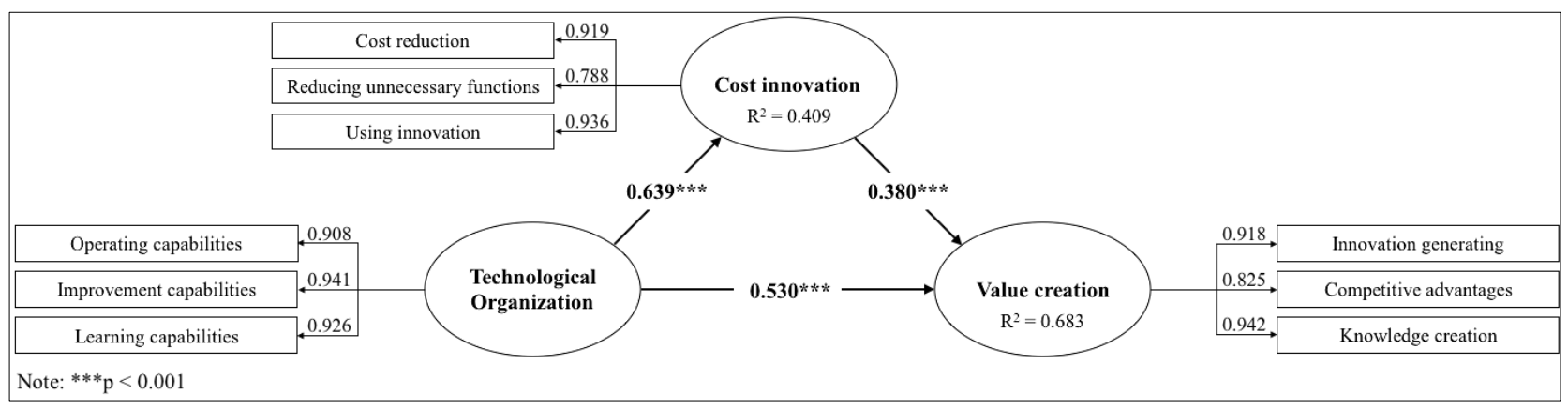

Figure 2. Result of the Structural Model

Table 6. Summary Results

\begin{tabular}{cccccc}
\hline Hypotheses & Effects & $\boldsymbol{\beta}$ & t-values & p-values & Fail to reject $\mathbf{H}_{\mathbf{0}}$ \\
\hline H1 & Technological Organization $\rightarrow$ Cost Innovation & $0.639 * * *$ & 8.234 & 0.000 & YES \\
H2 & Technological Organization $\rightarrow$ Value Creation (Direct effect) & $0.530 * * *$ & 4.420 & 0.000 & YES \\
- & Technological Organization $\rightarrow$ Value Creation (Indirect effect) & $0.243 * * *$ & 3.300 & 0.001 & - \\
H3 & Cost Innovation $\rightarrow$ Value Creation & $0.380 * * *$ & 3.182 & 0.001 & YES \\
\hline
\end{tabular}

Note: $* * * \mathrm{p}<0.001$, one-tailed test.

Being a technological organization has a significant positive effect on organizational value creation $(\beta=0.530, \mathrm{t}=$ $4.420, \mathrm{p}=0.000$ ); thus, $\mathrm{H} 2$ is supported. The technological organization incentivizes the company to use technologies for empowering other capabilities. As a result, the company will integrate those capabilities to create value, innovation, and competitive advantage. For example, the study of value co-creation and technological progression concludes that some customers that are opinion leaders, active learners, and innovators, in general, are those who will likely be the ones who will likely get involved in joint value co-creation through advanced information and communication technologies of the company [75]. According to the study in technology SMEs in India, it is confirmed that R\&D intensity positively affects organizational performance [76]. The enhancement of technologies in the organization serves as a catalyst to encourage the development of strategic resources, supporting firms to succeed and maintain a competitive advantage with implications for future organizational performance [77]. One of the components of value creation in this study is knowledge creation. The empirical study supports the notion that higher levels of IT have a positive effect on knowledge creation in universities [78]. In Barua's [79] work, the finding presents that information technology development positively affects knowledge creation in organizations. The researcher explains that just the availability of IT cannot lead to knowledge creation. The importance is the potentiality of employees to use and access new technologies, including enhancing knowledge transfer through IT. This point is in line with the technological organization that emphasizes the operating, improving, and learning technologies in the organization. Despite the controversy over the huge investments in developing a company into a technological organization, the long-term benefits are considered a worthwhile investment. Each company varies in structures and opportunities; as a result, the technology investment is different. Optimum technology investment strategies can assist the company gain profitability and performance [80].

In addition, being a technological organization has a significant positive indirect effect on organizational value creation $(\beta=0.243, \mathrm{t}=3.300, \mathrm{p}=0.001)$, and cost innovation management acts as the mediator of this relationship. The study of big data empowered agility for dynamic, volatile, and time-sensitive service industries can help companies visualize more clearly. Big data technology refers to a specific indicator for the massive assembly of data that increases enormously in size and exponentially with time. The study highlights the necessity of information and communication technology (ICT) infrastructure, platforms, and software to effectively gather and analyze big data. The analysis accurately predicts customer needs; as a result, the company can use the data analysis results to improve products or services in order to add value and customer experience [81]. It is in line with a digital platform assisting the company to add a new value creation, improve organizational efficiency, provide an approach for accessing external capabilities and resources, and share information [82]. The use of customer demand data to improve a product or service can be carried out by implementing cost innovation concepts as presented in this study by building cost advantages, reducing unnecessary functions, and developing innovation of self-use in the organization. The empirical research proves the effects of digital technology capability and organizational performance. The results find that digital technology capability indirectly affects organizational performance through innovation. It led to the conclusion that digital technologies in the organization can support creating innovation to increase productivity, get better access to customers, and reduce operating costs [72].

Cost innovation management has a significant positive effect on the organizational value creation $(\beta=0.380, t=3.182$, $\mathrm{p}=0.001$ ); thus, H3 is supported. Cost innovation management aims to reduce costs for competitive advantages [54] 
which is one of the components of value creation in this study. Reducing costs is achieved by selecting strategies, analyzing the lifecycle cost of products, reducing functions that are not responsive to customer needs, and applying innovations. These factors help companies create competitive advantages through lower production costs and lower service prices. Companies can use technology to identify customer needs and learn from direct competitors to better understand and develop their products or services. It will affect the development and innovation creation of the company in the long term. Effective cost reduction enhances an organization's value creation activity and creates competitive advantages [53]. The results of this study are consistent with Beheshti's [83] work. A company can achieve a competitive advantage when it develops overall cost leadership without neglecting quality and service. Although operating a business in a highly competitive environment, the competitive advantage of being a low-cost producer can earn above-average returns. As a result, the company can reinvest in and purchase innovations, technologies, and facilities to perpetuate the low-cost position. According to an empirical study of Indian low-cost carriers, this industry focuses on cost and price reductions to gain a competitive advantage. The results show that the resources and marketing of these low-cost companies positively affect profitability and growth [84].

\section{5- Conclusion}

The research results verify that developing a company into a technological organization will encourage cost innovation management and value creation. Besides, cost innovation management also leads to the development of value creation. Therefore, if a business needs to generate value creation, it is necessary to plan and determine the strategies in order to develop the company into a technological organization. Organizations should focus on improving the ability of employees to use existing technology effectively by promoting activities to increase technological knowledge, skills, and experience. Executives should be aware of external technology and support technology improvements in the organization. It can be seen that technology is a vital mechanism driving business during the COVID-19 outbreak. As a result, technology organizations will have an advantage over others that do not implement the same strategies. This research has presented the idea of cost innovation, which is a method that organizations can use to manage operating costs. Using technology to obtain customer information will support the development of products and services that better meet customer demands. Some customers may not want the highest level of functionality or technology, which is costly, but they want a more affordable and practical product. Thus, reducing unnecessary functions while still maintaining customer satisfaction is a choice of cost reduction because the company does not need to invest in manufacturing or providing services that customers do not want. Companies may choose to relocate their production bases in emerging countries to take advantage of labor and raw material costs. In addition, the company may use innovation to help increase production by decreasing cycle time, reducing waste, increasing efficiency, or using fewer raw materials. The results of this empirical study will fill academic gaps and also benefit executives in choosing and implementing strategies for business development and retention throughout the COVID-19 pandemic.

\section{5-1- Limitations and Future Research}

The research has some limitations that should be addressed. First, it used cross-sectional data collection during the COVID-19 pandemic, the results clarify the model in this specific context. The causal relationships may differ in normal conditions. Longitudinal or causal-comparative research could prove this limitation and confirm the results. Second, the consideration of the types of technology in a technology organization is broad, without specifying which technology is of particular importance. The researchers tried to compare their findings with the studies of fundamental technologies, such as digital and information technology. Therefore, future technologies, such as artificial intelligence (AI), chatbots, robotics, etc., are not mentioned. Third, according to the analysis of the structural model, some VIF values lie between 3 to 5 which shows that the model may have possible collinearity issues.

Future research may study technological organizations focused on a particular technology, such as 3D printing, AI robotics, or big data technology. Proposing simultaneously, the new approach that is Cost Innovation connects with such particular technology for expanding knowledge. The research may study the business environment as a moderator variable to investigate the relationship between technological organization and cost innovation management under different conditions. Structural models may be supplemented with interesting variables, such as co-value creation, ecoinnovation, and leveraging creativity, to increase the dimension of the relationships among variables.

\section{6- Declarations}

\section{6-1- Author Contributions}

Conceptualization, S.A. and K.J.; methodology, J.R.; software, K.J.; data curation, K.J.; writing —original draft preparation, J.R., S.A. and K.J.; writing-review and editing, Y.S. and K.J.; project administration, S.A.; funding acquisition, S.A. All authors have read and agreed to the published version of the manuscript.

\section{6-2- Data Availability Statement}

The data presented in this study are available in the article. 


\section{6-3- Funding}

This research was financially supported by the new strategic research (P2P) project (CGS-P2P-2565-016), Walailak University, Thailand.

\section{6-4- Institutional Review Board Statement}

This research was approved by the Institutional Review Board (IRB) of the human research ethics committee of Walailak University (WUEC-20-346-01).

\section{6-5- Conflicts of Interest}

The authors declare that there is no conflict of interests regarding the publication of this manuscript. In addition, the ethical issues, including plagiarism, informed consent, misconduct, data fabrication and/or falsification, double publication and/or submission, and redundancies have been completely observed by the authors.

\section{7- References}

[1] Food and Agriculture Organization. (2017). The future of food and agriculture-Trends and challenges. FAO, Annual Report, 296, 1-180. Available online: https://www.fao.org/3/i6583e/i6583e.pdf (accessed on December 2021).

[2] Baxter, W. (2017). Thailand 4.0 and the future of work in the kingdom. Freelance Journalist, Issue March, 1-16. Available online: https://www.ilo.org/wcmsp5/groups/public/---dgreports/---dcomm/documents/meetingdocument/wcms_549062.pdf (accessed on December 2021).

[3] Sisang, K., Jamieson, I., Wongwatcharapaiboon, J., \& Chulerk, R. (2020). SATI (Smarter Agriculture Thai Initiative): A Smarter Organic Farming Model for Thai Farmers. In Proceedings of the 11th Built Environment Research Associates Conference, Vol. 25, (BERAC2020), Bangkok, Thailand.

[4] Yaklai, P., Suwunnamek, O., \& Srinuan, C. (2018). How intellectual capital, knowledge management, and the business environment affect Thailand's food industry innovation. Asia-Pacific Social Science Review, 18(3), 30-42.

[5] Siripanwattana, C., Chandrachai, A., \& Keeratipibul, S. (2018). Organizational Knowledge and Skills, Managerial Attitudes and Performances regarding Foods Safety in food Manufacturing Firms in Thailand. Asian Journal of Applied Sciences, 6(5), 333342. doi:10.24203/ajas.v6i5.5469.

[6] Ministry of Commerce Thailand. (2021). Exports group structure. (In Thai). Available online: http://tradereport.moc.go.th/ TradeEng.aspx (accessed on December 2021).

[7] Williamson, P. J. (2010). Cost innovation: Preparing for a "value-for-money" revolution. Long Range Planning, 43(2-3), 343353. doi:10.1016/j.lrp.2009.07.008.

[8] Bergek, A., Tell, F., Berggren, C., \& Watson, J. (2008). Technological capabilities and late shakeouts: Industrial dynamics in the advanced gas turbine industry, 1987-2002. Industrial and Corporate Change, 17(2), 335-392. doi:10.1093/icc/dtn005.

[9] Wang, Y., Lo, H., Zhang, Q., \& Xue, Y. (2006). How technological capability influences business performance. Journal of Technology Management in China, 1(1), 27-52. doi:10.1108/17468770610642740.

[10] Zawislak, P. A., Alves, A. C., Tello-Gamarra, J., Barbieux, D., \& Reichert, F. M. (2012). Innovation capability: From technology development to transaction capability. Journal of Technology Management and Innovation, 7(2), 14-25. doi:10.4067/s071827242012000200002 .

[11] Ahmad, N., Othman, S. N., \& Mad Lazim, H. (2014). A review of technological capability and performance relationship in manufacturing companies. ISTMET 2014 - 1st International Symposium on Technology Management and Emerging Technologies, Proceedings, 193-198. doi:10.1109/ISTMET.2014.6936505.

[12] Agrawal, P., Narain, R., \& Ullah, I. (2020). Analysis of barriers in implementation of digital transformation of supply chain using interpretive structural modelling approach. Journal of Modelling in Management, 15(1), 297-317. doi:10.1108/JM2-032019-0066.

[13] Steil, A. V., de Cuffa, D., Iwaya, G. H., \& Pacheco, R. C. dos S. (2020). Perceived learning opportunities, behavioral intentions and employee retention in technology organizations. Journal of Workplace Learning, 32(2), 147-159. doi:10.1108/JWL-042019-0045.

[14] Čater, T., Čater, B., Černe, M., Koman, M., \& Redek, T. (2021). Industry 4.0 technologies usage: motives and enablers. Journal of Manufacturing Technology Management, 32(9), 323-345. doi:10.1108/JMTM-01-2021-0026.

[15] Hess, T., Benlian, A., Matt, C., \& Wiesböck, F. (2016). Options for formulating a digital transformation strategy. MIS Quarterly Executive, 15(2), 123-139. doi:10.4324/9780429286797-7. 
[16] Sagieva, G., \& Kotsemir, M. (2018). Measuring technological level of organisations: methodological approaches and assessment. Foresight, 20(4), 416-442. doi:10.1108/FS-03-2018-0026.

[17] Wu, X., Gu, Z., \& Zhang, W. (2008). The construction of innovation networks and the development of technological capabilities of industrial clusters in China. International Journal of Innovation and Technology Management, 5(2), 179-199. doi:10.1142/S0219877008001321.

[18] Costa, L., \& De Queiroz, S. R. R. (2002). Foreign direct investment and technological capabilities in Brazilian industry. Research Policy, 31(8-9), 1431-1443. doi:10.1016/S0048-7333(02)00073-2.

[19] Kumar, V., Kumar, U., \& Persaud, A. (1999). Building technological capability through importing technology: The case of Indonesian manufacturing industry. Journal of Technology Transfer, 24(1), 81-96. doi:10.1023/A:1007728921126.

[20] Wei, L. (1995). International technology transfer and development of technological capabilities: A theoretical framework. Technology in Society, 17(1), 103-120. doi:10.1016/0160-791X(94)00028-C.

[21] Lee, J., Bae, Z. -t, \& Choi, D. -k. (1988). Technology development processes: A model for a developing country with a global perspective. R\&D Management, 18(3), 235-250. doi:10.1111/j.1467-9310.1988.tb00590.x.

[22] Ostraszewska, Z., \& Tylec, A. (2015). Reverse innovation - how it works. International Journal of Business and Management, III(1), 57-74. doi:10.20472/bm.2015.3.1.004.

[23] Bengtsson, L., \& Wang, W. (2016). Cost innovation in global supply chains: The case of Huawei Technologies. International Journal of Logistics Systems and Management, 23(2), 189-208. doi:10.1504/IJLSM.2016.073969.

[24] Zeng, M., \& Williamson, P. J. (2007). Dragons at your door (pp. 1-10). Harvard Business School Press, Boston, United States.

[25] Wunker, S., \& Law, J. L. (2018). Costovation: Innovation That Gives Your Customers Exactly What They Want--And Nothing More. AMACOM, New York, United States.

[26] Leliveld, A., \& Knorringa, P. (2018). Frugal Innovation and Development Research. European Journal of Development Research, 30(1), 1-16. doi:10.1057/s41287-017-0121-4.

[27] Arshad, H., Radić, M., \& Radić, D. (2018). Patterns of Frugal Innovation in Healthcare. Technology Innovation Management Review, 8(4), 28-37. doi:10.22215/timreview/1150.

[28] Lehner, A.-C., Koldewey, C., \& Gausemeier, J. (2018). Approach for a Pattern-Based Development of Frugal Innovations. Technology Innovation Management Review, 8(4), 14-27. doi:10.22215/timreview/1149.

[29] Cadeddu, S. B. M., Layton, N., Banes, D., \& Cadeddu, S. (2019). Frugal innovation and what it offers the assistive technology sector. Global Perspectives on Assistive Technology, 487.

[30] Cadeddu, S. B. M., Layton, N., Banes, D., \& Cadeddu, S. (2019). Frugal innovation and what it offers the assistive technology sector. In N. Layton, \& J. Borg, (Eds.), Global perspectives on assistive technology: Proceedings of the GReAT Consultation 2019, Volume 2, 487-502. World Health Organization, Geneva, Switzerland.

[31] Weyrauch, T., \& Herstatt, C. (2017). What is frugal innovation? Three defining criteria. Journal of Frugal Innovation, 2(1), 117. doi:10.1186/s40669-016-0005-y.

[32] Hyypiä, M., \& Khan, R. (2018). Overcoming Barriers to Frugal Innovation: Emerging Opportunities for Finnish SMEs in Brazilian Markets. Technology Innovation Management Review, 8(4), 38-48. doi:10.22215/timreview/1151.

[33] Hossain, M., Simula, H., \& Halme, M. (2016). Can frugal go global? Diffusion patterns of frugal innovations. Technology in Society, 46(August 2016), 132-139. doi:10.1016/j.techsoc.2016.04.005.

[34] Hossain, M. (2017). Mapping the frugal innovation phenomenon. Technology in Society, 51(1), 199-208. doi:10.1016/j.techsoc.2017.09.006.

[35] Leliveld, A., \& Knorringa, P. (2018). Frugal Innovation and Development Research. European Journal of Development Research, 30(1), 1-16. doi:10.1057/s41287-017-0121-4.

[36] Agnihotri, A. (2015). Low-cost innovation in emerging markets. Journal of Strategic Marketing, $23(5), 399-411$. doi:10.1080/0965254X.2014.970215.

[37] Le Bas, C. (2020). Frugal innovation as environmental innovation. International Journal of Technology Management, 83(1-3), 78-96. doi:10.1504/IJTM.2020.109231.

[38] Michael, P. E. (1985). Competitive advantage: creating and sustaining superior performance. London Free Press, Ontario, Canada.

[39] Buytendijk, F. (2006). The Five Keys to Building a High-Performance Organization. Business Performance Management, 4(February), 24-30. 
[40] Le, P. B., \& Lei, H. (2018). The effects of innovation speed and quality on differentiation and low-cost competitive advantage: The case of Chinese firms. Chinese Management Studies, 12(2), 305-322. doi:10.1108/CMS-10-2016-0195.

[41] Gammeltoft, P. (2004). Development of firm-level technological capabilities: The case of the Indonesian electronics industry. Journal of the Asia Pacific Economy, 9(1), 49-69. doi:10.1080/13547860310001628294.

[42] Müller, J. M., Kiel, D., \& Voigt, K. I. (2018). What drives the implementation of Industry 4.0? The role of opportunities and challenges in the context of sustainability. Sustainability (Switzerland), 10(1), 247. doi:10.3390/su10010247.

[43] Wilson, G. (1995). Technological Capability, NGOs, and Small-Scale Development Projects. Development in Practice, 5(2), 128-142. doi:10.1080/0961452951000157104.

[44] Khan, F., \& Haleem, A. (2008). Role of technological and people capabilities in India: An empirical study. Global Journal of Flexible Systems Management, 9(2-3), 31-40. doi:10.1007/bf03396541.

[45] De Mori, C., Batalha, M. O., \& Alfranca, O. (2016). A model for measuring technology capability in the agrifood industry companies. British Food Journal, 118(6), 1422-1461. doi:10.1108/BFJ-10-2015-0386.

[46] Bowman, C., \& Ambrosini, V. (2000). Value Creation Versus Value Capture: Towards a Coherent Definition of Value in Strategy. British Journal of Management, 11(1), 1-15. doi:10.1111/1467-8551.00147.

[47] Lepak, D. P., Smith, K. G., \& Taylor, M. S. (2007). Value creation and value capture: A multilevel perspective. Academy of Management Review, 32(1), 180-194. doi:10.5465/AMR.2007.23464011.

[48] Zhu, X., Xiao, Z., Dong, M. C., \& Gu, J. (2019). The fit between firms' open innovation and business model for new product development speed: A contingent perspective. Technovation. 86-87(August), 75-85. doi:10.1016/j.technovation.2019.05.005.

[49] Brown, S. L., \& Eisenhardt, K. M. (1997). The art of continuous change: Linking complexity theory and time-paced evolution in relentlessly shifting organizations. Administrative Science Quarterly, 42(1), 1-34. doi:10.2307/2393807.

[50] Priem, R. L. (2007). A consumer perspective on value creation. Academy of Management Review, 32(1), 219-235. doi:10.5465/AMR.2007.23464055.

[51] Teece, D. J., Pisano, G., \& Shuen, A. (1997). Dynamic capabilities and strategic management. Strategic management journal, 18(7), 509-533. doi.org/10.1002/(SICI)1097-0266(199708)18:7<509::AID-SMJ882>3.0.CO;2-Z.

[52] Zollo, M., \& Winter, S. G. (2002). Deliberate learning and the evolution of dynamic capabilities. Organization Science, 13(3), 339-351. doi:10.1287/orsc.13.3.339.2780.

[53] Nahapiet, J., \& Ghoshal, S. (1998). Social capital, intellectual capital, and the organizational advantage. Academy of Management Review, 23(2), 242-266. doi:10.5465/AMR.1998.533225.

[54] Costa, J., \& Matias, J. C. O. (2020). Open innovation 4.0 as an enhancer of sustainable innovation ecosystems. Sustainability (Switzerland), 12(19), 8112. doi:10.3390/su12198112.

[55] Panda, H., \& Ramanathan, K. (1996). Technological capability assessment of a firm in the electricity sector. Technovation, 16(10), 561-588. doi:10.1016/S0166-4972(97)82896-9.

[56] Lichtenthaler, U. (2016). Determinants of absorptive capacity: the value of technology and market orientation for external knowledge acquisition. Journal of Business and Industrial Marketing, 31(5), 600-610. doi:10.1108/JBIM-04-2015-0076.

[57] Fang, C., Chang, S., \& Chen, G. (2011). Organizational learning capability and organizational innovation: The moderating role of knowledge inertia. African Journal of Business Management, 5(5), 1864-1870. doi:10.5897/AJBM10.947.

[58] Santos-Vijande, M. L., López-Sánchez, J. Á., \& Trespalacios, J. A. (2012). How organizational learning affects a firm’s flexibility, competitive strategy, and performance. Journal of Business Research, 65(8), 1079-1089. doi:10.1016/j.jbusres.2011.09.002.

[59] Moon, H., \& Lee, C. (2015). Strategic learning capability: through the lens of environmental jolts. European Journal of Training and Development, 39(7), 628-640. doi:10.1108/EJTD-07-2014-0055.

[60] Booker, D. M., Drake, A. R., \& Heitger, D. L. (2007). New Product Development: How Cost Information Precision Affects Designer Focus and Behavior in a Multiple Objective Setting. Behavioral Research in Accounting, 19(1), 19-41. doi:10.2308/bria.2007.19.1.19.

[61] Janz, D., \& Westkämper, E. (2007). Design to life cycle by value-oriented life cycle costing. Advances in Life Cycle Engineering for Sustainable Manufacturing Businesses - Proceedings of the 14th CIRP Conference on Life Cycle Engineering, 461-466. doi:10.1007/978-1-84628-935-4_80.

[62] Dunk, A. S. (2012). Assessing the Contribution of Product Life Cycle Cost Analysis, Customer Involvement, and Cost Management to the Competitive Advantage of Firms. Management Accounting, 20(1), 29-45. doi:10.1108/s14747871(2012)0000020008. 
[63] Pham, T. P., \& Quddus, A. (2021). The Impact of Innovation Activities on Firm Efficiency: Data Envelopment Analysis. Journal of Asian Finance, Economics and Business, 8(3), 0895-0904. doi:10.13106/jafeb.2021.vol8.no3.0895.

[64] Kock, N., \& Hadaya, P. (2018). Minimum sample size estimation in PLS-SEM: The inverse square root and gamma-exponential methods. Information Systems Journal, 28(1), 227-261. doi:10.1111/isj.12131.

[65] Hair, J. F., Risher, J. J., Sarstedt, M., \& Ringle, C. M. (2019). When to use and how to report the results of PLS-SEM. European Business Review, 31(1), 2-24. doi:10.1108/EBR-11-2018-0203.

[66] Saraiva, M., Novas, J. C., Ferreira, O., \& Pires, A. R. (2017). ISO 9001 Quality Management Systems: A Systematic Literature Review. TMQ-Techniques, Methodologies and Quality, Nº, Lisboa: Associação Portuguesa para a Qualidade (APQ), 8, 11-43.

[67] Henseler, J., Ringle, C. M., \& Sarstedt, M. (2015). A new criterion for assessing discriminant validity in variance-based structural equation modeling. Journal of the Academy of Marketing Science, 43(1), 115-135. doi:10.1007/s11747-014-0403-8.

[68] Hair, J. F., Hult, G. T. M., Ringle, C. M., Sarstedt, M., Danks, N. P., \& Ray, S. (2021). Partial Least Squares Structural Equation Modeling (PLS-SEM) Using R. Classroom Companion: Business. doi:10.1007/978-3-030-80519-7.

[69] Shmueli, G., \& Koppius, O. R. (2011). Predictive analytics in information systems research. MIS Quarterly: Management Information Systems, 35(3), 553-572. doi:10.2307/23042796.

[70] Shmueli, G., Ray, S., Velasquez Estrada, J. M., \& Chatla, S. B. (2016). The elephant in the room: Predictive performance of PLS models. Journal of Business Research, 69(10), 4552-4564. doi:10.1016/j.jbusres.2016.03.049.

[71] Peter, M. K., Kraft, C., \& Lindeque, J. (2020). Strategic action fields of digital transformation: An exploration of the strategic action fields of Swiss SMEs and large enterprises. Journal of Strategy and Management, 13(1), 160-180. doi:10.1108/JSMA05-2019-0070.

[72] Parker, G. G., Alstyne, M. W. Van, \& Choudary, S. P. (2016). Platform Revolution: How Networked Markets Are Transforming the Economy. In W. W. Norton \& Company, New York, United States.

[73] Khin, S., \& Ho, T. C. F. (2019). Digital technology, digital capability and organizational performance: A mediating role of digital innovation. International Journal of Innovation Science, 11(2), 177-195. doi:10.1108/IJIS-08-2018-0083.

[74] Vakeel, K. A., Malthouse, E. C., \& Yang, A. (2020). Impact of network effects on service provider performance in digital business platforms. Journal of Service Management, 32(4), 461-482. doi:10.1108/JOSM-04-2020-0120.

[75] Hamad, H., Elbeltagi, I., \& El-Gohary, H. (2018). An empirical investigation of business-to-business e-commerce adoption and its impact on SMEs competitive advantage: The case of Egyptian manufacturing SMEs. Strategic Change, 27(3), $209-229$. doi:10.1002/jsc.2196.

[76] Zhang, T., Lu, C., Torres, E., \& Cobanoglu, C. (2020). Value co-creation and technological progression: a critical review. European Business Review, 32(4), 687-707. doi:10.1108/EBR-08-2019-0149.

[77] Chatterjee, M., \& Bhattacharjee, T. (2020). Ownership concentration, innovation and firm performance: empirical study in Indian technology SME context. South Asian Journal of Business Studies, 10(2), 149-170. doi:10.1108/SAJBS-10-2019-0185.

[78] O’Shannassy, T. (2008). Sustainable competitive advantage or temporary competitive advantage: Improving understanding of an important strategy construct. Journal of Strategy and Management, 1(2), 168-180. doi:10.1108/17554250810926357.

[79] Saide, S., Indrajit, R. E., Trialih, R., Ramadhani, S., \& Najamuddin, N. (2019). A theoretical and empirical validation of information technology and path-goal leadership on knowledge creation in university: Leaders support and social media trend. Journal of Science and Technology Policy Management, 10(3), 551-568. doi:10.1108/JSTPM-06-2018-0067.

[80] Barua, B. (2021). Impact of total quality management factors on knowledge creation in the organizations of Bangladesh. TQM Journal, 33(6), 1516-1543. doi:10.1108/TQM-06-2020-0145.

[81] Chhabra Roy, N. (2021). Banks and their technology investment decision are aligned or not - an experience of Indian banks. Journal of Facilities Management, 19(1), 1-20. doi:10.1108/JFM-04-2020-0020.

[82] Stylos, N., Zwiegelaar, J., \& Buhalis, D. (2021). Big data empowered agility for dynamic, volatile, and time-sensitive service industries: the case of tourism sector. International Journal of Contemporary Hospitality Management, 33(3), $1015-1036$. doi:10.1108/IJCHM-07-2020-0644.

[83] Li, T. C., \& Chan, Y. E. (2019). Dynamic information technology capability: Concept definition and framework development. The Journal of Strategic Information Systems, 28(4), 101575. doi.org/10.1016/j.jsis.2019.101575.

[84] Beheshti, H. M. (2004). Gaining and sustaining competitive advantage with activity based cost management system. Industrial Management \& Data Systems, 104(5), 377-383. doi:10.1108/02635570410537462.

[85] Singh, V., Vaibhav, S., \& Sharma, S. K. (2018). Using structural equation modelling to assess the sustainable competitive advantages provided by the low-cost carrier model: The case of Indian airlines. Journal of Indian Business Research, 13(1), 4377. doi:10.1108/JIBR-12-2017-0260. 